\title{
Single Platform for Gene and Protein Expression Analyses Using Luminescent Gold Nanoclusters
}

\author{
Sunil Kumar Sailapu, ${ }^{\dagger} \odot$ Deepanjalee Dutta, ${ }^{\dagger}$ Amaresh Kumar Sahoo, ${ }^{\dagger}, \|$ Siddhartha Sankar Ghosh, ${ }^{*}, \dagger, \ddagger \odot$ \\ and Arun Chattopadhyay, ${ }^{*},, \$(0)$
}

${ }^{\dagger}$ Centre for Nanotechnology, ${ }^{\ddagger}$ Department of Biosciences and Bioengineering, and ${ }^{\S}$ Department of Chemistry, Indian Institute of Technology Guwahati, Guwahati 781 039, Assam, India

\section{Supporting Information}

\begin{abstract}
A single platform for gene and protein expression studies is proposed to pursue rapid diagnostics. A common method to synthesize gold ( $\mathrm{Au})$ nanoclusters on both DNA and protein template was developed using a benchtop device. The method of synthesis is rapid and versatile and can be applied to different classes of DNA/protein. Employing luminescent $\mathrm{Au}$ nanoclusters as the signalgenerating agents, the device enables carrying out reverse transcriptase polymerase chain reaction and array-based analyses of multiple genes/proteins simultaneously using switchable holders and custom-designed software. The device and methods were applied to evaluate gene profiling related to apoptosis in HeLa cancer cells and further to analyze the protein expressions of glutathione-S-transferase (GST) and GST-tagged human granulocyte macrophage colony-stimulating factor (GSThGMCSF) recombinant proteins purified from bacterial strains of BL21(DE3) Escherichia coli (E. coli). The device with user-friendly methods for diagnosis using the luminescence of $\mathrm{Au}$ nanoclusters offers potential use in disease diagnostics with a vision to extend health care facilities especially to remote geographical locations.
\end{abstract}

\section{INTRODUCTION}

Analyses of genes and proteins can be considered as two pillars key to the molecular basis of health analysis. An important aspect is to develop new methods and devices for the analyses so that not only faster and sensitive techniques are made available but also a broad spectrum of the global populace can accrue the benefit of such developments. This can possibly be achieved by combining the best of well-established conventional gene and protein analysis protocols and currently developing fields such as nanomaterials with extraordinary optical properties.

Recent technological developments, in fields of genomics and proteomics, have helped to provide vital information coded in DNA and proteins to predict potential disease targets and mutations, to infer on disease susceptibility, and to discover novel therapeutic agents. ${ }^{1,2}$ The reverse transcriptase polymerase chain reaction (RT-PCR, in the case of genes) and high-throughput array-based methods (for analyses of genes and proteins) have been central to the achievements. ${ }^{3,4}$ However, the advancements have been associated with sophisticated instrumentation, complex and multistep fabrication and analysis techniques, and involved processes for functionalization of the probes to achieve high sensitivity and selectivity. ${ }^{5-8}$ Although an advanced technique such as quantitative PCR (qPCR) can be implemented for real-time sample analysis, its usage is not deemed necessary in many cases. Another technique, loop-mediated isothermal amplification though promising, suffers from drawbacks such as complicated primer designing method, challenges during multiplexing, contamination and cannot be used for the amplification of sequences of size $>300 \mathrm{bp}$. Hence, semiquantitative PCR has remained a standard technique in molecular diagnostics. Some of the earlier reported devices (with thermocyclers and optical detection systems) were designed for performing real-time PCR (or quantitative RTPCR) and are generally adopted for a limited number of samples (one to four) at a time. ${ }^{9,10}$ However, it is equally important to develop devices and easy methods to be applicable in routine usages where the semiquantitative PCR assay can be viewed as an useful alternative. A key aspect in PCR carried out by specific primers is detection of DNA amplicons through staining techniques for understanding the presence or absence of a particular gene. These semiquantitative PCR-based approaches could serve as a first-principle assay for understanding the infection status or the presence of a particular genetic material (as well as protein) for which qPCR is not mandatory. Additionally, there is concern over the use of hazardous organic dyes and radioactive isotopes which are less common but still considered for the staining of nucleic acids and proteins. ${ }^{11,12}$ Most of the organic dyes used as probes in staining techniques such as ethidium bromide (EtBr) were found to be cytotoxic and mutagenic. Other alternatives such as SYBRSafe, SafeView, RedSafe, and so forth, which are generally marketed as safe, were found to be able to permeate the cell membrane very rapidly and

Received: November 7, 2017

Accepted: February 7, 2018

Published: February 21, 2018 
Scheme 1. (A) Layout of the Device and Schematic Illustrations of (B) Gene Expression Studies and (C) Protein Expression Studies $^{a}$

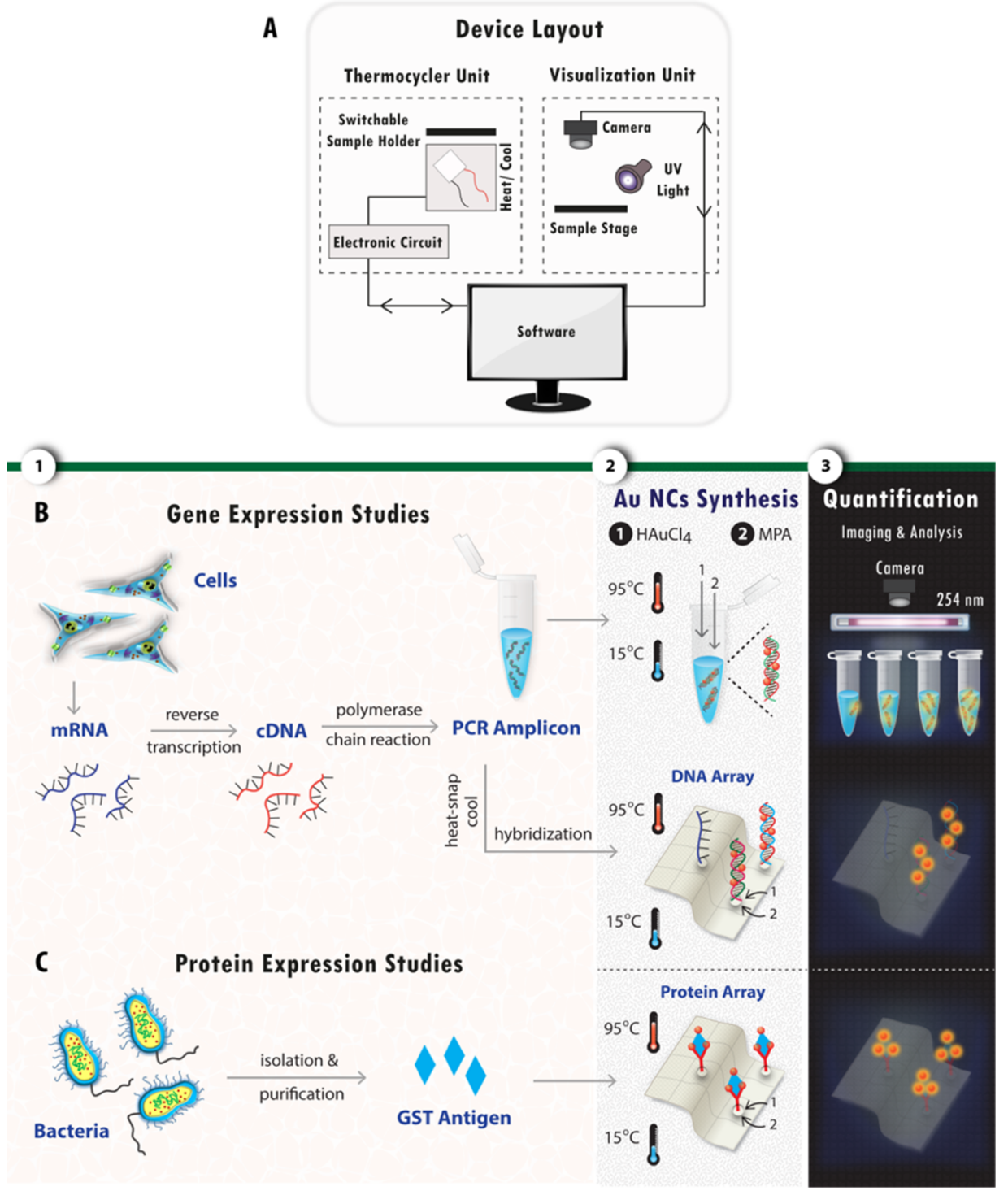

${ }^{a}$ For gene expression studies: (i) Amplification of DNA: genes of interest in the cDNA (cDNA converted from isolated RNA of cells) were amplified using the device. Synthesis of Au nanoclusters was then carried out on the PCR amplicon (in the tube) in a single temperature cycle using the thermocycler unit. The Au nanoclusters synthesized in the PCR products were imaged in the visualization unit under UV illumination. The intensities of emissions from the Au nanoclusters were analyzed using the software to generate information about amplification; (ii) DNA array: the PCR amplicons were heated and snap-cooled to obtain single-stranded products using the device and they were then spotted over the nitrocellulose membrane containing preimmobilized complementary ssDNA. Au nanoclusters were synthesized in a single temperature cycle on these spots and the membrane was imaged and analyzed in a similar way as described before. For protein expression studies: glutathione-S-transferase (GST) antigens were extracted and purified from E. coli BL21 (DE3) bacteria and were spotted on polyvinylidene difluoride (PVDF) membrane containing preimmobilized GST antibodies. Synthesis of Au nanoclusters was carried out on these spots using a single temperature cycle and the membrane was imaged and analyzed as detailed above. Here, NCs stand for nanoclusters.

bind to DNA. They also show cytotoxicity and mutagenicity after metabolic activation. Importantly, current methods commonly use multiple probes (signal-generating agents) for the detection of both DNA and protein, thus lacking universality of approach leading to careful design optimizations of techniques and could be costly. Alternatively, one could develop new technology that would unify both the gene and protein analyses in a single platform by virtue of single biofriendly signal-generating probe to achieve rapid staining techniques. This would allow easy access of rapid diagnostics by a large population at an affordable cost. ${ }^{13,14}$ The efficiency of the PCR process has been improved through the usage of metal nanoparticles, quantum dots, carbon nanotubes, carbon nanoparticles, graphene, etc. ${ }^{15-18}$ The plasmonic $^{19,20}$ and luminescent ${ }^{21}$ nanomaterials are useful as diagnostic probes in PCR and array-based methods. However, because of high sensitivity and background-related issues, fluorometric techniques are preferred over colorimetric assays. ${ }^{22}$ Use of conventional organic fluorophores is limited because of photobleaching, photoblinking, and often the carcinogenic nature of the molecule. Though quantum dots have been used as fluorometric tags in gene and protein expression studies as better materials, their toxicity is a concern. ${ }^{23-25}$ It is also worth 


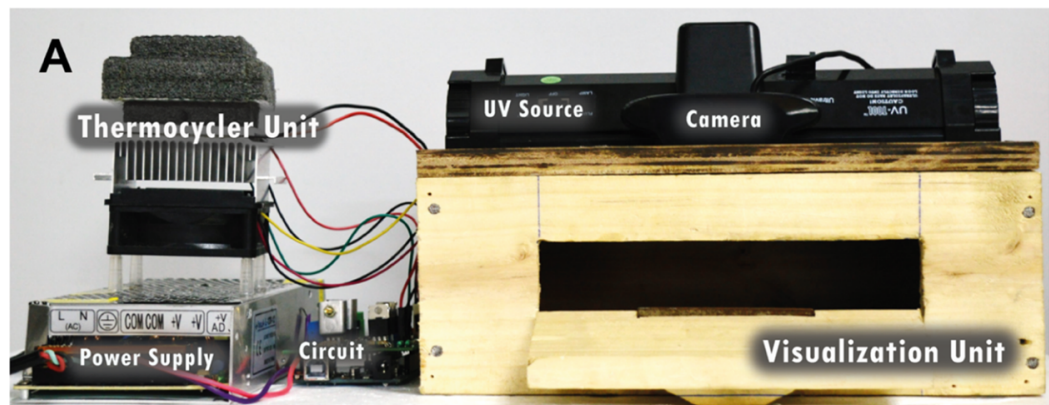

B

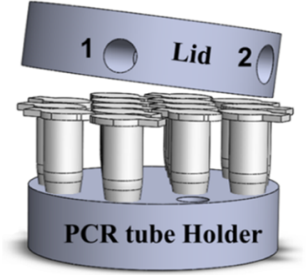

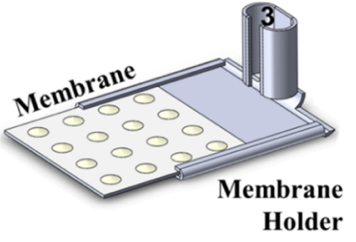

$1,3=$ Slot for temperature sensor

$2=$ Slot for heating element

Figure 1. (A) Benchtop device for carrying out RT-PCR and DNA/protein array-based analyses. (B) Switchable holders to accommodate either commercially available PCR tubes or membrane (for array-based analysis). The figure shows the graphical representation of the holders and lid- $0.2 \mathrm{~mL}$ PCR tube holder with lid on the top and membrane holder for array-based studies.

noting here that most of the diagnostic techniques (for RT-PCR and microarray) adopt initial synthesis of nanomaterials followed by specific functionalization for conjugation with biomolecules. This particular approach demands extra labor (such as isolation of the probe) and processing and is thus time-consuming, making them not suitable for fast detection. Also, as interaction with biomolecules occurs post nanomaterials' synthesis, there lies a possibility that their complete conjugation may be difficult to achieve because of potential loss of functionality to some extent. Validation in every step is necessary to certify the functionality, which is vital for subsequent interactions to occur. Alternatively, few atom luminescent metal nanoclusters are an exciting option as fluorophores because of their salient features including small size, high photostability, low toxicity with respect to other fluorophores, and low photoblinking. ${ }^{23}$ Recently, these metal nanoclusters have been applied as luminescent probes for various applications. ${ }^{26-30}$ Biomolecules such as DNA and proteins have been reported to be capable of directing the synthesis of fluorescent metal nanoclusters. Gold nanoclusters were also reported to be less cytotoxic and have good renal clearance as suggested by in vivo studies. However, extensive applications of these nanoclusters have so far been limited in rapid detection assays involving DNA and proteins because of the requirement of a large amount of precursors, a longer time period of synthesis, and extensive purification steps. ${ }^{31,32}$ In the current context, to employ them as signal-generating agents for both PCR and arraybased techniques, the synthesis should be rapid, applicable for both DNA and protein (as direct template) in liquid as well as in solid phase. Provided such an efficient synthesis procedure is obtained integrating into the core functionality of PCR and arraybased studies, it could pave for the development of a device with common mode of detection for the study of genes and proteins.

We report a single platform based approach for carrying out RT-PCR (nucleic acid amplification) and array-based analysis of multiple genes/proteins with luminescent $\mathrm{Au}$ nanoclusters as signal-generating agents using a benchtop device as illustrated in Scheme 1 . The synthesis of $\mathrm{Au}$ nanoclusters (signal-generating probes) involved a rapid single-step method and can be carried out directly using DNA or protein. This synthesis of Au nanoclusters on the PCR products in the tube itself or on the hybridized PCR products in the nitrocellulose membrane or purified protein bound to an antibody attached to polyvinylidene difluoride (PVDF) membrane was achieved using the device itself and was all possible in one platform (Scheme 1). The synthesis was carried out in a rather short time to achieve nearly homogeneous $\mathrm{Au}$ nanoclusters without any need for further processing and thereby making it an excellent choice in applications as the diagnostic probe. The luminescence of the Au nanoclusters was proportional to the amount of the template present, that is, either DNA or protein concentration. Hence, study of the luminescence profile revealed the nature of reactions/interactions occurred provided there was a change in the amount of the biomolecule. This principle of detection was applied for the semiquantitative analysis of PCR products and for the array-based analysis of multiple samples of DNA and protein. In the case of PCR amplicon quantification, the device facilitated direct analysis of PCR products using the luminescence of the $\mathrm{Au}$ nanoclusters within the PCR tube, thus avoiding the additional step of gel electrophoresis. Paper-based membrane methods were adopted for array-based analysis to avoid complex fabrication procedure and made the whole process less expensive, easy to handle, flexible, and disposable so that the technique can easily be adopted for medical diagnostics even in remote areas. $^{33,34}$ The traditional dot-blot assays are useful for the analysis of a small number of samples and are viable alternatives to highly sophisticated microarray platforms especially in the case of first-principle analysis. The ability to carry out membranebased studies with rapid synthesis of $\mathrm{Au}$ nanoclusters using the device is an important element in the current study. To the best of our knowledge, the devices for qPCR with optical detection setup do not provide such a rapid detection platform for the membrane-based analysis of both genes and proteins using a single probe as demonstrated in the present work. Moreover, the current approach helps to avoid cross-contamination, which was observed in most of the devices based on microfluidics approach for $\mathrm{qPCR}^{9}$ 
The device and the methods proposed have been applied to evaluate gene profiling for the apoptotic pathway, where HeLa cancer cells were treated with a commercially available drug doxorubicin and their apoptotic gene expression profile was studied by $\mathrm{Au}$ nanocluster luminescence in an array-based method as illustrated in Scheme 1B and was compared with conventional $\mathrm{EtBr}$ staining. Also, for the study of protein expression, clinically important protein glutathione-S-transferase (GST) and GST-tagged human granulocyte macrophage colonystimulating factor (GST-hGMCSF) expressed in Escherichia Coli (E. coli) BL21 (DE3) were used. The expressions were studied using array-based methods using the same device as shown in Scheme 1C, following purification and capture by an immobilized anti-GST antibody. The results matched with conventional sodium dodecyl sulfate polyacrylamide gel electrophoresis (SDS-PAGE).

\section{RESULTS AND DISCUSSION}

Benchtop Device Hardware and Software. The device is modular in design and constitutes two major blocksthermocycler and visualization unit (Figures $1 \mathrm{~A}$ and S1). The device is interfaced with computer/laptop and controlled through custom-developed software as shown in the Supporting Information, Figures S2 and S3. The software can access both the blocks and allow entering device-related parameters, controlling the sequence of operations, performing image acquisition, and carrying out analysis. The thermocycler unit is used to achieve temperature cycling necessary for carrying out the RT-PCR process, gene/protein array-based experiments, and synthesis of $\mathrm{Au}$ nanoclusters on DNA/protein both in the liquid phase and on the membrane. This unit is equipped with switchable sample holders to accommodate both commercially available PCR tubes and the membrane (for array-based analysis), thus facilitating easy switching between the two process as per need (Figure 1B). The bottom of the holder is exposed to Peltier unit (that is connected to heatsink and fan), which heats and cools the sample holder. The temperature of the holders can reach between 10 and $100{ }^{\circ} \mathrm{C}$. For a PCR tube holder, the average ramp rate is about $0.95{ }^{\circ} \mathrm{C} / \mathrm{s}$ (heating) and $1{ }^{\circ} \mathrm{C} / \mathrm{s}$ (cooling). On the other hand, the average ramp rate for the membrane holder is about $1.2^{\circ} \mathrm{C} / \mathrm{s}$ (heating) and $1.3{ }^{\circ} \mathrm{C} / \mathrm{s}$ (cooling). For the PCR process, a lid is placed on the top of the tube and is kept in hot condition to avoid condensation because of evaporation of the liquid. The temperature of the lid can quickly go up to $120{ }^{\circ} \mathrm{C}$ in about $150 \mathrm{~s}$ from room temperature $\left(22^{\circ} \mathrm{C}\right)$. Both the holders and the lid are equipped with sensors for monitoring the temperatures. A custom-designed-embedded circuit is the core electronic element responsible for the operation of the thermocycler. $\mathrm{Au}$ nanoclusters could be synthesized using the thermocycler unit itself with respective holders either inside the PCR tube (in the case of DNA) or on the membrane (in the case of gene/protein arrays). The visualization unit consists of a UV light source (254 $\mathrm{nm}, 6 \mathrm{~W}$, with option for interchangeable UV sources-short, mid, and long wavelength) to provide illumination to the samples. It also features a camera source for visualization and imaging of the samples (through the luminescence of the synthesized $\mathrm{Au}$ nanoclusters). The design of the device offers considerable advantages: (1) the switchable holders give the feasibility to carry out PCR and array-based studies of both DNA and proteins in both liquid and solid phases on a single platform. (2) The method involving the synthesis of Au nanoclusters could be integrated in the device alongside the conventional techniques. (3) The modular optimization of the thermocycler and visualization unit (with imaging capabilities) provides a compact, cost-effective platform for DNA and protein studies. Moreover, these units could be independently used for different purposes. For example, although we used UV source for illumination in our current study in the visualization unit, it could be easily adapted to provide a wide range of excitation wavelengths. (4) The developed software, besides augmenting the operation experience, would allow complete analysis of samples.

PCR Amplification and Quantification Employing Au Nanoclusters. To evaluate the performance of the device toward DNA amplification, $\beta$-actin gene was amplified using specific primers-for 35 cycles. A similar set was amplified in a commercial PCR machine (Palm cycler), keeping the conditions of amplification same in both the cases. Standard gel electrophoresis with $\mathrm{EtBr}$ staining methods was employed to analyze the PCR amplicons. The gel images of the PCR amplicons as visualized in the gel documentation system are shown in the Supporting Information, Figure S4. Image analysis (densitometry) of gel bands revealed that a gene amplification efficacy of about $95 \%$ could be obtained using the device, in comparison to a commercial PCR machine. Instead of tedious gel electrophoresis and use of EtBr for quantifying PCR products, ${ }^{35}$ we devised a method to use luminescent Au nanoclusters to visualize the PCR amplicons following amplification in the device. We had earlier reported $^{36}$ the development of a temperature-dependent facile and rapid synthesis of Au nanoclusters for DNA quantification. Adopting a single heating and cooling cycle-based synthesis (the condition similar to the conventional PCR) gives an advantage of synthesizing the Au nanoclusters probe alongside PCR for gene quantification. The current synthesis is found to be not affected by base pair compositions and sequence lengths. ${ }^{36}$ On the other hand, importantly, the luminescence of the formed $\mathrm{Au}$ nanoclusters was found to be affected only by the amount of dsDNA used for the synthesis, thus providing a method for semiquantification. Here, the same protocol was adopted with the flexibility to carry out the same in the PCR tube after gene amplification. The synthesis used the final PCR amplicon as the template with $\mathrm{HAuCl}_{4}$ and 3-mercaptopropionic acid (MPA) as the reagents and was subjected to a single heating and cooling cycle (between the temperatures 95 and $15{ }^{\circ} \mathrm{C}$ ) in the thermocycler unit. This resulted in the synthesis of $\mathrm{Au}$ nanoclusters in proportion to the amount of PCR amplicons (Supporting Information, Figure S5A). The Au nanoclusters exhibited luminescence with a peak at $585 \mathrm{~nm}$, when excited by $254 \mathrm{~nm}$ light (Supporting Information, Figure S5B). PCR amplicons or DNA acted as a stabilizer by providing steric protection along with MPA (auxiliary small-molecule stabilizer) which passivates the $\mathrm{Au}$ nanoclusters through $-\mathrm{S}-\mathrm{Au}$ bond linkages. It could be possible that the clusters were stabilized by both DNA and - COO- groups of MPA. In addition, MPA also contributed to the reduction of $\mathrm{AuCl}_{4}^{-}$to produce nanoclusters. $^{37,38}$ To employ these Au nanoclusters in quantification as signal-generating agents, $\beta$-actin gene was amplified for different cycles (e.g., 20, 25, 30, and 35) using specific primers in the thermocycler unit of the device. Then, Au nanoclusters were synthesized on the PCR amplicons by adding the reagents ( $\mathrm{HAuCl}_{4}$ and MPA) to the PCR tube, followed by heating to 95 ${ }^{\circ} \mathrm{C}$ for $2 \mathrm{~min}$ and then cooling down to $15^{\circ} \mathrm{C}$ for $3 \mathrm{~min}$. The PCR tubes were then directly imaged in the visualization unit under UV excitation of $254 \mathrm{~nm}$, and the image, shown in Figure 2, was captured. It was observed that as the amount of the available template (end-point PCR amplicon) increases with the number 


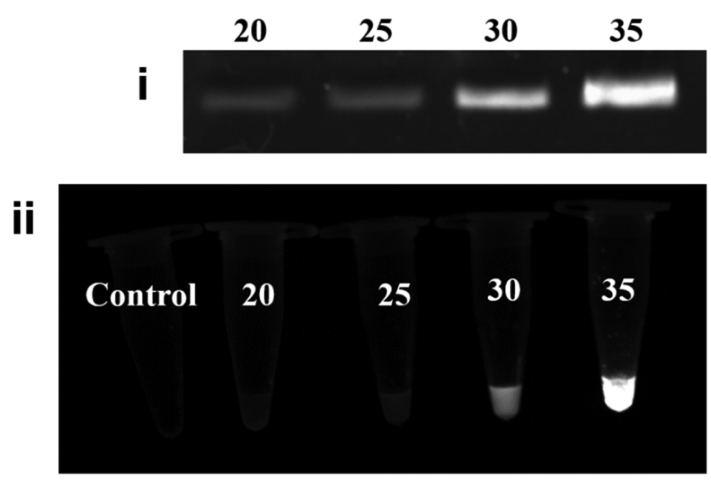

Figure 2. $\beta$-actin gene was amplified using specific primers using the present device-for $20,25,30$, and 35 cycles. (i) Gel images corresponding to various cycles of EtBr-stained PCR products under UV illumination. (ii) Grayscale image of Au nanoclusters synthesized on different cycles of PCR amplicons under UV excitation $(254 \mathrm{~nm})$.

of cycles of amplification, the formation of Au nanoclusters also increases monotonically, generating higher luminescence. Further, the luminescence of the synthesized Au nanoclusters provided a way for the semiquantification of the PCR products which is essential in ascertaining the presence/absence of a particular gene. It was also observed that the lowest amount of DNA that the synthesized Au nanoclusters could differentiate was for 20 cycles (starting with $0.5 \mu \mathrm{g}$ of DNA). Another similar set was amplified for different cycles and validated by a standard process of agarose gel electrophoresis (with EtBr staining), which was in good agreement with the results obtained.

Gene Expression Analysis. These results encouraged us to extend the application of the device for studying the expression of multiple genes simultaneously in an array format, using these $\mathrm{Au}$ nanoclusters as the signal-generating agents. To achieve this, commercially obtained single-stranded oligonucleotide ( $\beta$-actin) probes, in increasing concentrations, were immobilized in two rows on a nitrocellulose membrane. Commercially obtained complementary target strands were then hybridized on the spots in the second row only as shown in the Supporting Information, Figure S6. Au nanoclusters were then synthesized on all the spots in the membrane in the thermocycler unit as described above. Upon imaging in the visualization unit, the luminescence of the Au nanoclusters was evident in the spots of the membrane and it was observed that, for each concentration, the intensity in hybridized dsDNA spot was more in comparison to that in the control ssDNA spot, that is, for each of those spots present in the second row.

Commercially obtained sequences of common apoptotic genes (BCL-2, BAX, and Caspase-3) were chosen with the idea of extending the application of $\mathrm{Au}$ nanoclusters toward apoptotic gene expression profiling. $\mathrm{Au}$ nanoclusters were synthesized on different amounts of hybridized dsDNA for each set of genes. It was observed that, in each case, with the increase in the amount of the hybridized product, the luminescence increased proportionately, as shown in the Supporting Information, Figure S7. A set of experiments were

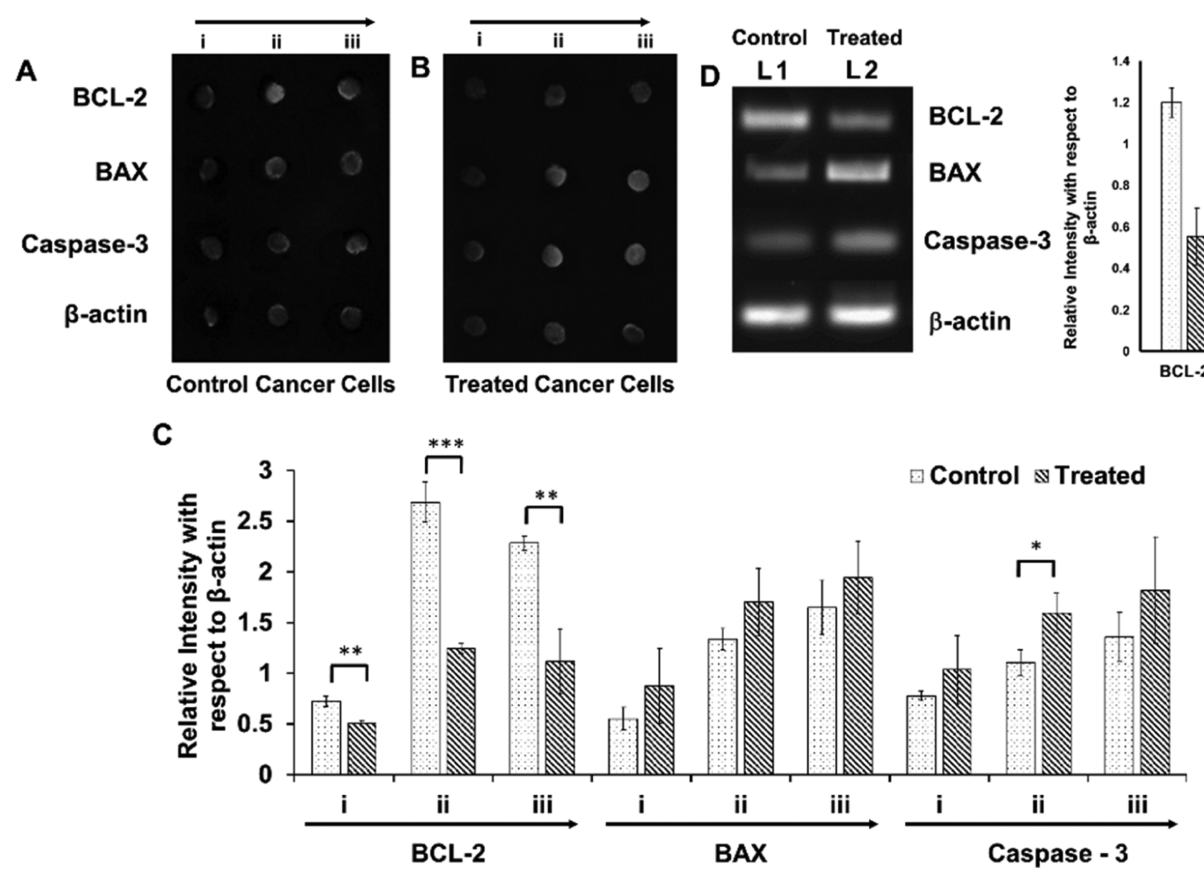

Figure 3. Study of expression of multiple genes in control HeLa cells and doxorubicin-treated HeLa cells. (A), (B) Grayscale images under UV illumination $(254 \mathrm{~nm})$ of Au nanoclusters synthesized on various genes (spots) in control and treated HeLa cells. First, commercially obtained ssDNA (as the capture agent) of BCL-2, BAX, and Caspase-3 in increasing amounts ((i) 0.18, (ii) 0.37, and (iii) $0.74 \mu \mathrm{g}$; indicated by the arrow) were immobilized on the nitrocellulose membrane in a single row. Following this, increasing amounts of PCR amplicons of BCL-2, BAX, and Caspase-3 for (i) 0.18 , (ii) 0.37 , and (iii) $0.74 \mu \mathrm{g}$ obtained from control and doxorubicin-treated cells were heated and snap-cooled to achieve single-stranded products and were subsequently hybridized to the above-mentioned capture probes in the specific row, respectively. Au nanoclusters were then synthesized on all the spots of the membrane. (C) Relative luminescence intensity of Au nanoclusters synthesized on BCL-2, BAX, and Caspase-3-hybridized dsDNA in control and treated HeLa cells (obtained following the image analysis). The graph depicts the averaged intensity of data (relative to $\beta$-actin gene) from three separate experiments with their standard deviation. (D) Gel electrophoresis with EtBr staining of PCR amplicons of BCL-2, BAX, and Caspase-3 from control and treated HeLa cells. L1 and L2 lanes correspond to control and treated samples. Experiments were done in triplicates, $* P<0.05$ with respect to control, $* * P<0.01$ with respect to control, and $* * * P<0.001$ with respect to control. 
also performed with $\mathrm{Au}$ nanoclusters synthesized on noncomplementary pairs of commercially obtained sequences. The analysis showed that the luminescence intensity of noncomplementary pairs was similar to that of ssDNA controls immobilized on the membrane, as shown in the Supporting Information, Figure S8, possibly because of washing away of the noncomplementary strands. These results suggest that the luminescent $\mathrm{Au}$ nanoclusters are a viable alternative to commonly used organic dyes for studying gene expression.

For the application of Au nanoclusters in the study of relative gene expressions during apoptosis in cancer cells, in vitro, relative gene expression studies were carried out in HeLa cells, which were subjected to apoptosis via anticancer drug doxorubicin. The apoptosis specific genes in control and doxorubicin-treated cells (BCL-2, BAX, and Caspase-3) were then amplified, in the device, using gene-specific primers. Commercially obtained corresponding ssDNA apoptotic marker genes were immobilized on the nitrocellulose membrane in increasing amounts per spot. After this, PCR amplicons were heated and then snap-cooled in the thermocycler (to obtain single-stranded products), and they were subsequently transferred to the above spots containing ssDNA. Following hybridization, Au nanoclusters were synthesized on these spots, and the gene regulation outputs were quantified in correlation to the luminescence profile. As is evident from the relative intensities in Figure 3, the apoptotic genes BAX and Caspase- 3 were upregulated and BCL-2 was downregulated with respect to endogenous control $\beta$-actin, signifying apoptosis in the case of doxorubicin-treated HeLa cells in comparison to that in the control HeLa cells. Here, we would like to mention that there is an apparent anomaly in the observed data related to the concentration of $0.74 \mu \mathrm{g}$ of BCL-2, which is expected to result in the highest luminescence among the set. This is caused because of the possible saturation of the luminescence at concentration above $0.37 \mu \mathrm{g}$, and any further increase in concentration caused a decrease in luminescence intensity, as observed at $0.74 \mu \mathrm{g}$. However, this does not affect the primary aim to understand the difference between the control and treated samples and could be well-demarcated (at $0.74 \mu \mathrm{g}$ ) irrespective of the decrease in luminescence. Conventional $\mathrm{EtBr}$ gel electrophoresis studies corroborated the aforementioned results obtained by the use of $\mathrm{Au}$ nanoclusters. Hence, $\mathrm{Au}$ nanoclusters were successfully applied to probe the expressions of multiple genes governing the apoptosis pathway in the HeLa cells. The short time and minimum precursor requirement compared to earlier reports ${ }^{39,40}$ make the Au nanocluster probe ideal for point-of-care detection. In addition, the current method did not form any larger-sized $\mathrm{Au}$ nanoparticles alongside $\mathrm{Au}$ nanoclusters, which was generally observed in previously reported works. ${ }^{39,40}$ Also, the current method was applicable for the synthesis of Au nanoclusters on both linear and plasmid forms of DNA. To the best of our knowledge, there is no report of a common method for the formation of $\mathrm{Au}$ nanoclusters on both linear and plasmid forms. These Au nanoclusters were also found to be biocompatible and noncytotoxic. ${ }^{36}$

Rapid Synthesis of Au Nanoclusters with Proteins. Building on the successful applications of $\mathrm{Au}$ nanoclusters in assaying DNA, we developed a novel method of synthesizing $\mathrm{Au}$ nanoclusters on protein templates. This was to combine protein expression studies alongside gene analysis in the same device. The synthesis in the presence of proteins also involved a singlestep heating and cooling cycle with similar precursors as in the case of DNA. Au nanoclusters were synthesized on bovine serum albumin (BSA) as the template- using $\mathrm{HAuCl}_{4}$ and MPA as the reagents - by heating to $95^{\circ} \mathrm{C}$ for 2 min and cooling to $15^{\circ} \mathrm{C}$ for $3 \mathrm{~min}$. Au nanoclusters thus formed emitted luminescence at 580 $\mathrm{nm}$, when excited by $300 \mathrm{~nm}$ light. The formation of the nanoclusters was found to be dependent on the amount of protein. Also, the nanocluster synthesis is not specific to particular protein sequence, and this has been demonstrated using different classes of proteins. The versatility makes this assay applicable to a wide range of proteins, which is necessary for diagnostic applications (Supporting Information, Figure S9). The luminescence profile of the $\mathrm{Au}$ nanoclusters for a range of concentrations of protein (BSA) and $\mathrm{HAuCl}_{4}$ is shown in the Supporting Information, Figure S10. The surface intensity plot (Supporting Information, Figure S10) indicated that the luminescence intensity increased with the amount of $\mathrm{HAuCl}_{4}$ (or protein) for a range of concentrations of either protein (or $\mathrm{HAuCl}_{4}$ ), followed by decrease in the luminescence after a certain concentration. As in the above case with PCR amplicons/ DNA, proteins are also a well-known template for nanocluster synthesis. Hence, similar to the nanocluster synthesis using DNA, here protein acted as the stabilizer with MPA as a reducing agent. The fluorescence spectrum of only $\mathrm{MPA}$ and $\mathrm{HAuCl}_{4}$ showed the formation of extremely low-intensity $\mathrm{Au}$ nanoclusters, while no formation of Au nanoclusters was found in the case of only protein and $\mathrm{HAuCl}_{4}$. However, in the presence of protein along with MPA and $\mathrm{HAuCl}_{4}$, the intensity of the formed Au nanoclusters was significantly high and was also found to be stable in nature. Transmission electron microscopy (TEM) showed the formation of small particles owing to Au nanoclusters and also indicated an increase in the particle size from $0.75 \pm 0.27$ to $5.81 \pm 2.05 \mathrm{~nm}$, with increasing concentrations of $\mathrm{HAuCl}_{4}$ (Supporting Information, Figure S11). Also, circular dichroism (CD) spectroscopy revealed that the formation of $\mathrm{Au}$ nanoclusters did not alter significantly the 3D structure of BSA (Supporting Information, Figure S12). The photoluminescence quantum yield of $\mathrm{Au}$ nanoclusters on proteins was found to be $4.5 \%$, thus making them suitable for sensing applications. Also, when compared to an organic dye rhodamine $6 \mathrm{G}$ with the fluorescence decrease rate of $2.7 \%$ per min, the Au nanoclusters showed a fluorescence decrease rate of $0.26 \%$ per min, indicating higher photostability (Supporting Information, Figure S13). The matrix-assisted laser desorption/ionization time-of-flight (MALDI-TOF) analysis (Supporting Information, Figure S14) showed a distinct peak at $71171(\mathrm{~m} / \mathrm{z})$. The $\mathrm{m} / \mathrm{z}$ difference between BSA and $\mathrm{Au}$ nanoclusters is $4350.8(\mathrm{~m} / z)$, favoring possible formation of $\left(\mathrm{Au}_{16}(\mathrm{MPA})_{11}+2 \mathrm{Na}^{+}-\mathrm{H}^{+}\right)^{-1}$ corresponding to a metal cluster with $16 \mathrm{Au}$ atoms.

Protein Expression Analysis. For the application of these $\mathrm{Au}$ nanoclusters in protein expression studies, the expression profiling of GST and GST-hGMCSF in E. coli BL 21 (DE3) cells was performed after their isolation and purification. The integrity and functionality of the isolated proteins (GST and GSThGMCSF) were analyzed by using standard SDS-PAGE, CD spectroscopy, Bradford assay, and 1-chloro-2,4-dinitrobenzene (CDNB) assay (Supporting Information, Figures S15 and S16). In SDS-PAGE, bands corresponding to GST and GST-hGMCSF were observed at 26 and $42 \mathrm{kDa}$, respectively, and concentrations of the proteins obtained from the Bradford assay were 239 and 96 $\mu \mathrm{g} / \mathrm{mL}$ for GST and GST-hGMCSF, respectively. CD spectroscopy confirmed that $3 \mathrm{D}$ conformation of $\mathrm{GST}^{41}$ as well as GST$\mathrm{hGMCSF}^{42}$ was intact for functionality. Also, the CNDB assay specific for the determination of the GST enzyme activity confirmed that the GST was functional for both the cases of GST and GST-hGMCSF. 

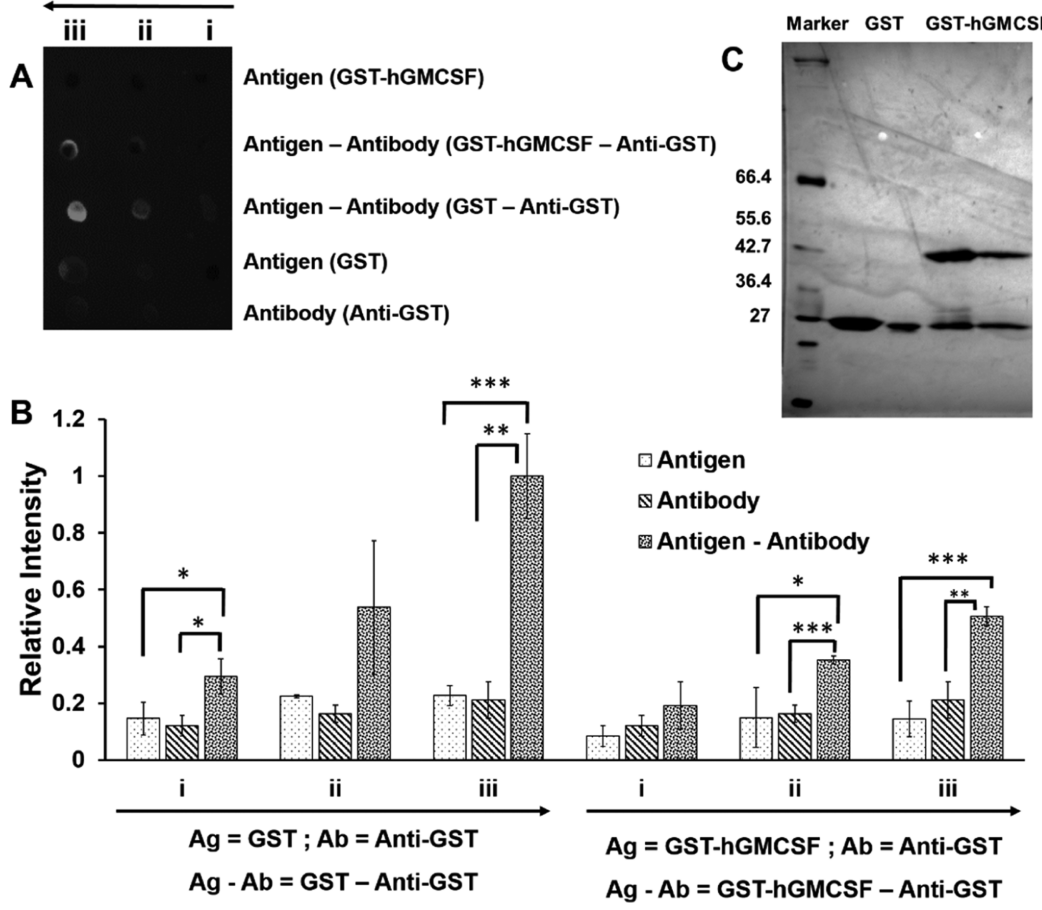

Figure 4. Study of expression of multiple proteins isolated from E. coli BL21 (DE3). (A) Grayscale images under UV illumination (254 nm) of Au nanoclusters synthesized on various proteins (spots). First, increasing concentrations ((i) 0.1 , (ii) 0.2 , and (iii) $0.4 \mu \mathrm{g}$ ) of anti-GST antibody were immobilized onto the PVDF membrane in two rows and interacted with increasing concentrations ((i) 0.08, (ii) 0.16 , and (iii) $0.32 \mu \mathrm{g}$ ) of GSThGMCSF in one row and with ((i) 0.1 , (ii) 0.2 , and (iii) $0.4 \mu \mathrm{g}$ ) of pure GST in another row. Only GST-hGMCSF, pure GST, and Ab (anti-GST) were also immobilized in separate rows on the PVDF membrane in increasing amounts for comparison and analysis. (B) Relative luminescence intensities (with respect to the maximum mean intensity in the entire data) of Au nanoclusters synthesized on spotted proteins as mentioned above. The graph depicts the averaged intensity of data from three separate experiments with their standard deviation. (C) SDS-PAGE analysis of pure GST and GSThGMCSF. Experiments were done in triplicates, ${ }^{*} P<0.05$ with respect to $\mathrm{Ag}$ or $\mathrm{Ab}, * * P<0.01$ with respect to $\mathrm{Ag}$ or $\mathrm{Ab}$, and $* * * P<0.001$ with respect to $\mathrm{Ag}$ or $\mathrm{Ab}$.

After obtaining the proteins (GST and GST-hGMCSF) in their functional forms, they were allowed to interact with their respective anti-GST antibodies previously immobilized on the PVDF membrane along with their GST, GST-hGMCSF, and anti-GST antibody controls. Then, Au nanoclusters were synthesized on the respective spots using the thermocycler unit in a single cycle of heating and cooling as in the case of DNA (described earlier). Thereafter, the membrane was imaged using the visualization unit, and the luminescence intensity of the $\mathrm{Au}$ nanoclusters was found to be the highest in the case of GSTanti-GST antibody conjugate followed by GST-hGMCSF-antiGST antibody conjugate, when compared to only GST, GSThGMCSF, and anti-GST antibody as shown in Figure 4. These results corroborated the standard SDS-PAGE and Bradford assay results obtained previously. As the formation of the nanoclusters was found to be dependent on the amount of protein, it was observed that in the case of immobilized antibodies, or only GST protein on the membrane, there was no visible formation of nanoclusters as an adequate amount of protein was absent in both these cases. Whereas when both the immobilized antibodies along with the GST protein were present together, the increase in the amount of the protein content led to the formation of nanoclusters. Hence, in the absence of the analyte, which can be either the antibody or the antigen depending on the assay, the luminescence will not be generated or will be always less compared to the antigen-antibody conjugate. As a control experiment, specific GST protein and a nonspecific BSA protein interacted with the anti-GST antibody, and it was found that the luminescence did not get enhanced in the case of BSA as it did with increasing concentrations of GST, possibly because of washing away of the nonspecific BSA antigen (Supporting Information, Figure S17). Hence, it can be concluded that the luminescent Au nanoclusters, synthesized in situ, were efficient probes for the protein expression studies. The same advantages as mentioned above for the use of Au nanoclusters as probes for gene expression studies also apply for the protein expression studies. The rapid method of synthesis directly on PCR products/proteins with minimum precursor concentrations, biocompatibility, and concentration-dependent luminescence makes the current study an important addition in the analysis of gene/protein expression.

Enhancement of Sensitivity with Zinc Ions. It may further be mentioned here that in array-based analysis, involving either gene or protein, addition of zinc ions during the synthesis of $\mathrm{Au}$ nanoclusters enhanced the luminescence intensity of the $\mathrm{Au}$ nanoclusters. As shown in the Supporting Information, Figure S18, in one of the rows, zinc ions were added during the synthesis of $\mathrm{Au}$ nanoclusters. As is evident from the image analysis, the luminescence intensity increased in the case where zinc ions were added to the reaction mixture. The reason for the increase in luminescence may be attributed to the aggregation of $\mathrm{Au}$ nanoclusters caused by zinc ions. ${ }^{43}$ Thus, this technique can be used for the enhancement of luminescence in the case of lower signal intensity.

\section{CONCLUSIONS}

We presented a single platform for the assaying of genes and proteins based on luminescent biofriendly Au nanoclusters using 
a benchtop device. The facile and rapid synthesis of biocompatible signal-generating agents ( $\mathrm{Au}$ nanoclusters) on both DNA and proteins allowed semiquantitative and qualitative analyses. Further, it provided a method of synthesis of $\mathrm{Au}$ nanoclusters as a common probe for both DNA and protein studies (in liquid as well as samples on the membrane), PCR amplicon detection, and membrane-based studies in a single device. The device was able to deliver PCR amplification efficiency of about $95 \%$ in comparison to the commercially available machine. The custom-developed software simplified the operation to enhance the user experience and to perform tasks like providing input parameters and image acquisition and analysis. The modular design of the device permits easy upgradation. Importantly, the techniques, methods, and materials employed are bio- and environmentally friendly. Taken into account all these sublime features, the device and the integrated methods may add a new dimension to the existing techniques with the amalgamation of nanotechnology and biology. This may create motivation to converge various techniques and develop methods in a view to make rapid diagnostics available to a majority of people across the globe.

\section{METHODS}

Amplification of DNA with the Device. $\beta$-actin gene was amplified for 35 cycles using specific primers in both the conventional PCR machine (Palm cycler) and the present device, keeping the conditions as initial denaturation at $95^{\circ} \mathrm{C}$ for $3 \mathrm{~min}$ followed by 35 cycles of three phases: $95^{\circ} \mathrm{C}$ for $30 \mathrm{~s}, 55^{\circ} \mathrm{C}$ for 30 $\mathrm{s}$, and $72{ }^{\circ} \mathrm{C}$ for $1 \mathrm{~min}$. After this, final extension was carried out at $72{ }^{\circ} \mathrm{C}$ for $10 \mathrm{~min}$. The PCR amplicons obtained from both the devices were analyzed using standard gel electrophoresis with $\mathrm{EtBr}$ staining. The stained gel was visualized under UV illumination as shown in the Supporting Information, Figure S4. The amplification achieved by the present device was about 95\% compared to conventional PCR machine as analyzed from the image.

Quantification of PCR Products Using Au Nanoclusters. Two sets of $\beta$-actin gene were amplified for $20,25,30$, and 35 cycles using specific primers using the thermocycler unit of the device with the conditions as initial denaturation at $95{ }^{\circ} \mathrm{C}$ for 3 min followed by the specific number of thermal cycles with each cycle as $95{ }^{\circ} \mathrm{C}$ for $30 \mathrm{~s}, 55^{\circ} \mathrm{C}$ for $30 \mathrm{~s}, 72^{\circ} \mathrm{C}$ for $1 \mathrm{~min}$, and final extension for $10 \mathrm{~min}$.

In the first set, $\mathrm{Au}$ nanoclusters were synthesized using the thermocycler with the following protocol. $\mathrm{HAuCl}_{4}(1.0 \mathrm{mM}, 17$ wt \% Au, in dilute $\mathrm{HCl} ; 99.99 \%$, Sigma-Aldrich) and $0.01 \mathrm{M}$ MPA (Sigma-Aldrich) were added in 3:1 (v/v) ratio to the endpoint PCR product (inside the PCR tube itself), heated at $95{ }^{\circ} \mathrm{C}$ for $2 \mathrm{~min}$, and then cooled at $15^{\circ} \mathrm{C}$ for $3 \mathrm{~min}$. This resulted in the formation of $\mathrm{Au}$ nanoclusters in proportion to the amplification. The final PCR tubes containing the PCR amplicons with synthesized Au nanoclusters were then imaged and analyzed using the visualization unit under UV excitation of $254 \mathrm{~nm}$. Standard gel electrophoresis with EtBr staining is carried out for the second set of PCR amplicons. The gel was visualized under UV illumination.

\section{Gene Expression Studies.}

a) cDNA extraction from control HeLa cells and doxorubicin-treated HeLa cells: HeLa cancer cells were cultured in two $60 \mathrm{~mm}$ culture plates with a cell density of $1 \times 10^{6}$ cells. Keeping one of the plates as the control, the other plate was treated with anticancer drug doxorubicin for 24 h. Using the standard RNA protocol, RNA was isolated from both the cells (control and treated). cDNA was obtained from mRNA using the thermocycler (at $42{ }^{\circ} \mathrm{C}$ for $40 \mathrm{~min}$ and $95^{\circ} \mathrm{C}$ for $2 \mathrm{~min}$ ) with Verso cDNA kit.

b) Amplification of specific genes using the thermocycler unit of the device: BAX, BCL-2, and Caspase- 3 along with endogenous control $\beta$-actin were amplified using specific primers for 35 cycles (denaturation: $95{ }^{\circ} \mathrm{C}$ for $3 \mathrm{~min}$; 35 cycles with three phases: $95{ }^{\circ} \mathrm{C}$ for $30 \mathrm{~s}, 55^{\circ} \mathrm{C}$ for $30 \mathrm{~s}, 72$ ${ }^{\circ} \mathrm{C}$ for $1 \mathrm{~min}$, and final extension for $10 \mathrm{~min}$ ).

c) Immobilization of complementary oligonucleotide on the nitrocellulose membrane: nitrocellulose membrane (Zeta Probe blotting membranes; cut to maximum dimensions of $40 \mathrm{~mm} \times 40 \mathrm{~mm}$ ) was activated in $1 \times$ SSC (saline sodium citrate) buffer and was allowed to air-dry. The commercial oligonucleotides were spotted and UV-cross linked in an array format by the standard process.

d) Hybridization of heated and snap-cooled PCR products to the complementary oligonucleotides immobilized on the nitrocellulose membrane: the PCR products were heated and snap-cooled and hybridized to their respective immobilized complementary nucleotides by the following process.

The membrane was blocked before hybridization using blocking solution (1\% PVP-10, 1\% PEG 6000, and 0.05\% Tween-20) for $15 \mathrm{~min}$ to avoid unspecific binding. The hybridization was carried out in $5 \times$ SSC buffer and $10 \%$ poly(ethylene glycol) (PEG) 6000 at $60{ }^{\circ} \mathrm{C}$ for half an hour. The membrane was then washed with $1 \mathrm{X}$ SSC buffer.

e) Synthesis of Au nanoclusters on a hybridized membrane: after hybridization, synthesis of $\mathrm{Au}$ nanoclusters was carried out on the spots by adding $1.5 \mu \mathrm{L}$ of $0.7 \mathrm{mM}$ $\mathrm{HAuCl}_{4}$ and $0.5 \mu \mathrm{L}$ of $0.01 \mathrm{M} \mathrm{MPA}$, followed by heating the membrane using the thermocycler at $95^{\circ} \mathrm{C}$ for $2 \mathrm{~min}$ and then cooling at $15{ }^{\circ} \mathrm{C}$ for $3 \mathrm{~min}$.

f) Image acquisition and analysis: the membrane with synthesized $\mathrm{Au}$ nanoclusters was imaged and analyzed using the visualization unit using custom-developed software under UV illumination $(254 \mathrm{~nm})$.

Synthesis of the Au Nanoclusters Using BSA as the Template. For synthesis, $20 \mu \mathrm{L}$ of $(0.05-1.0 \mathrm{mg} / \mathrm{mL}) \mathrm{BSA}$ (Himedia) was taken, and to that $0.4 \mu \mathrm{L}$ of $10 \mathrm{mM} \mathrm{HAuCl}_{4}$ and $0.16 \mu \mathrm{L}$ of $0.11 \mathrm{M}$ of MPA were added, and the mixture was heated at $95{ }^{\circ} \mathrm{C}$ for $2 \mathrm{~min}$ and then cooled at $15^{\circ} \mathrm{C}$ for $3 \mathrm{~min}$.

\section{Protein Expression Studies.}

a) Expression and purification of GST and GST-hGMCSF in Escherichia coli BL21 DE3: for primary culture, $20 \mu \mathrm{L}$ of $E$. coli BL21 DE3 stock harboring pGEX4t2 vector was inoculated in $3 \mathrm{~mL}$ of LB (Luria-Bertani) media with $3 \mu \mathrm{L}$ of $100 \mathrm{mg} / \mathrm{mL}$ ampicillin and was incubated overnight at $37{ }^{\circ} \mathrm{C}(180 \mathrm{rpm})$. The grown primary culture $(2 \mathrm{~mL})$ was inoculated into $200 \mathrm{~mL} \mathrm{LB}$ media with $200 \mu \mathrm{L}$ of $100 \mathrm{mg} /$ $\mathrm{mL}$ ampicillin and was incubated at $37^{\circ} \mathrm{C}(180 \mathrm{rpm})$ until an optical density (O.D.) of 0.6 was obtained. Following this, induction was given by $1 \mathrm{~mL}$ of isopropyl $\beta$-D-1thiogalactopyranoside $(24 \mathrm{mg} / \mathrm{mL})$ at $24{ }^{\circ} \mathrm{C}(180 \mathrm{rpm}, 6$ h). The cells were then centrifuged at $6000 \mathrm{rpm}\left(4^{\circ} \mathrm{C}, 7\right.$ $\mathrm{min})$, and the pellet hence obtained was stored at $-20^{\circ} \mathrm{C}$. For the preparation of lysis buffer $(7 \mathrm{~mL}), 100 \mu \mathrm{L}$ of $1 \mathrm{mM}$ ethylenediaminetetraacetic acid and $100 \mu \mathrm{L}$ of $1 \mathrm{mM}$ phenylmethane sulfonyl fluoride were added to $1 \mathrm{X}$ 
phosphate-buffered saline (PBS). The cell pellet was then resuspended in lysis buffer homogenously and was sonicated with a probe sonicator for $5 \mathrm{~min}$. Centrifugation was carried out at $12000 \mathrm{rpm}\left(4{ }^{\circ} \mathrm{C}, 20 \mathrm{~min}\right)$, and the supernatant was collected. The supernatant obtained in the previous step contained solubilized protein. It was first filtered through a $0.45 \mu \mathrm{m}$ syringe filter and was then put into a glutathione agarose beads column (prepared previously by the standard method) for half an hour. Flow-through fractions were collected, followed by washing of the column eight times with PBS. For elution buffer preparation, $20 \mathrm{mg}$ of reduced glutathione was added to $5 \mathrm{~mL}$ of $50 \mathrm{mM}$ tris ( $\mathrm{pH} 8$ ). Recombinant GST bound to the affinity column was eluted with the elution buffer after $20 \mathrm{~min}$. Multiple-flow through fractions were collected and analyzed using 12\% SDS PAGE. A similar protocol was adopted for the isolation and purification of GST-hGMCSF. $^{44}$

b) Estimation of protein by the Bradford assay: the concentration of the purified recombinant GST proteins was estimated using the Bradford assay. The standard solution was prepared using the BSA of concentrations 0.5 , $1,2,4$, and $10 \mu \mathrm{g} / \mathrm{mL}$, and $10 \mu \mathrm{L}$ of the protein sample (recombinant GST proteins) was used for analysis along with $90 \mu \mathrm{L}$ of Bradford reagent solution (Sigma-Aldrich). It was allowed to react at room temperature for $10 \mathrm{~min}$ in dark, and the optical density at $595 \mathrm{~nm}$ was measured using a TECAN Elisa plate reader.

c) Enzyme activity: GST activity was determined using the CDNB assay: the increasing amount of protein solutions with 1X PBS buffer (pH 7.5), $1.0 \mathrm{mM}$ GSH, and $1.0 \mathrm{mM}$ $\mathrm{CDNB}$, amounting to the total volume of $100 \mu \mathrm{L}$, was taken in a 96-well plate. The control wells contained PBS, $\mathrm{CDNB}$, and glutathione. After $10 \mathrm{~min}$, the change in absorbance with respect to control was measured at 340 $\mathrm{nm}$ using a Tecan Elisa plate reader. One unit of activity is defined as the formation of $1 \mu \mathrm{M}$ product per min at $25^{\circ} \mathrm{C}$ ( $\varepsilon_{\mathrm{mM}}$ is the extinction coefficient at $340 \mathrm{~nm}$ in a 96-well plate is 5.3 for $C D N B$, and $D$ is the dilution factor).

$$
\begin{aligned}
& \text { Change in absorbance }\left(\Delta A_{340}\right) / \mathrm{min} \\
& =\frac{A_{340 \text { final }}-A_{340} \text { initial }}{\text { reaction time }} \\
& \text { GST activity }(\mu \mathrm{mol} / \mathrm{mL} / \mathrm{min}) \\
& =\frac{\left(\Delta A_{340} / \mathrm{min}\right) \times V(\mathrm{~mL}) \times D}{V_{\text {enz }}(\mathrm{mL}) \times \varepsilon_{\mathrm{mM}}}
\end{aligned}
$$

d) Immobilization of primary antibody on the PVDF membrane in an array pattern: the primary antibody specific to the GST antigen was immobilized on the PVDF membrane (IMMOBILON P $0.45 \mu \mathrm{m}$ membrane) by spotting different dilutions of primary antibody after activating the membrane of suitable dimensions (with maximum dimensions of $40 \mathrm{~mm} \times 40 \mathrm{~mm}$ ) in methanol. After spotting, the membrane was allowed to air-dry for $15-20 \mathrm{~min}$

e) Interaction of antigens with antibodies on the PVDF membrane: the membrane was blocked using blocking solution (as mentioned above) for $30 \mathrm{~min}$ to avoid unspecific binding, after that the membrane was incubated with respective GST antigens for $30 \mathrm{~min}$ and was washed with PBST (PBS with Tween 20) buffer for reducing nonspecificity.

f) Synthesis of Au nanoclusters on the PVDF membrane: after antigen-antibody interactions, Au nanoclusters were synthesized on the spots, by adding $1.5 \mu \mathrm{L}$ of $0.7 \mathrm{mM}$ $\mathrm{HAuCl}_{4}$ and $0.5 \mu \mathrm{L}$ of $0.01 \mathrm{M} \mathrm{MPA}$ followed by heating the membrane using a thermocycler at $95^{\circ} \mathrm{C}$ for $2 \mathrm{~min}$ and then cooling at $15{ }^{\circ} \mathrm{C}$ for $3 \mathrm{~min}$.

g) Image acquisition and analysis: the membrane with synthesized $\mathrm{Au}$ nanoclusters was imaged and analyzed using the visualization unit using custom-developed software under UV illumination $(254 \mathrm{~nm})$.

Statiscal Analysis. Data were expressed as mean value \pm standard deviation (SD). Student's $t$-test was employed to test significant differences between the experimental groups. $(* P<$ $0.05, * * P<0.01, * * * P<0.001)$.

\section{ASSOCIATED CONTENT}

\section{S Supporting Information}

The Supporting Information is available free of charge on the ACS Publications website at DOI: 10.1021/acsomega.7b01739.

TEM, emission spectra, software snapshots, quantum yield, photostability, MALDI, CD spectroscopy, Bradford assay, enzyme activity assay, and membrane-based analysis (PDF)

\section{AUTHOR INFORMATION}

\section{Corresponding Authors}

*E-mail: sghosh@iitg.ernet.in (S.S.G.).

*E-mail: arun@iitg.ernet.in (A.C.).

ORCID $\odot$

Sunil Kumar Sailapu: 0000-0002-0923-0879

Deepanjalee Dutta: 0000-0002-4695-5262

Siddhartha Sankar Ghosh: 0000-0002-7121-5610

Arun Chattopadhyay: 0000-0001-5095-6463

\section{Present Address}

"Assistant Professor, Indian Institute of Information Technology, Allahabad, Uttar Pradesh 211012, India (A.M.S.).

\section{Author Contributions}

S.K.S contributed ideas and developed the device, designed experiments, analysed results. D.D. contributed ideas, designed and carried out experiments, and analyzed results. A.K.S. contributed ideas. S.S.G. contributed ideas and helped in analyses. A.C. conceived the idea and helped implement them. The manuscript was written through contributions of all authors. All authors have given approval to the final version of the manuscript.

\section{Funding}

We thank the Department of Electronics and Information Technology (no. 5(9)/2012-NANO (Vol. II)), Government of India for financial support.

\section{Notes}

The authors declare the following competing financial interest(s): an Indian as well as international patent application has been filed based on the content of the manuscript.

\section{REFERENCES}

(1) Lockhart, D. J.; Winzeler, E. A. Genomics, Gene Expression and DNA Arrays. Nature 2000, 405, 827-836.

(2) Tyers, M.; Mann, M. From Genomics to Proteomics. Nature 2003, 422, 193-197. 
(3) Gaj, S.; Eijssen, L.; Mensink, R. P.; Evelo, C. T. A. Validating Nutrient-Related Gene Expression Changes from Microarrays Using $\mathrm{Rt}^{2}$ PCR-Arrays. Genes Nutr. 2008, 3, 153-157.

(4) Brandt, S.; Kloska, S.; Altmann, T.; Kehr, J. Using Array Hybridization to Monitor Gene Expression at the Single Cell Level. J. Exp. Bot. 2002, 53, 2315-2323.

(5) Quijada, L.; Soto, M.; Requena, J. M. Genomic DNA Macroarrays as a Tool for Analysis of Gene Expression in Leishmania. Exp. Parasitol. 2005, 111, 64-70.

(6) Randolph, J. B.; Waggoner, A. S. Stability, Specificity and Fluorescence Brightness of Multiply-Labeled Fluorescent DNA Probes. Nucleic Acids Res. 1997, 25, 2923-2929.

(7) Moreira, B. G.; You, Y.; Owczarzy, R. Cy3 and Cy5 Dyes Attached to Oligonucleotide Terminus Stabilize DNA Duplexes: Predictive Thermodynamic Model. Biophys. Chem. 2015, 198, 36-44.

(8) Toutchkine, A.; Nalbant, P.; Hahn, K. M. Facile Synthesis of ThiolReactive Cy3 and Cy5 Derivatives with Enhanced Water Solubility. Bioconjugate Chem. 2002, 13, 387-391.

(9) Ahrberg, C. D.; Ilic, B. R.; Manz, A.; Neužil, P. Handheld real-time PCR device. Lab Chip 2016, 16, 586-592.

(10) Mulberry, G.; White, K. A.; Vaidya, M.; Sugaya, K.; Kim, B. N. 3D printing and milling a real-time PCR device for infectious disease diagnostics. PLoS One 2017, 12, No. e0179133.

(11) Espina, V.; Woodhouse, E. C.; Wulfkuhle, J.; Asmussen, H. D.; Petricoin, E. F., 3rd; Liotta, L. A. Protein Microarray Detection Strategies: Focus on Direct Detection Technologies. J. Immunol. Methods 2004, 290, 121-133.

(12) Morimatsu, K.; Wu, Y.; Kowalczykowski, S. C. RecFOR Proteins Target RecA Protein to a DNA Gap with Either DNA or RNA at the 5' Terminus IMPLICATION FOR REPAIR OF STALLED REPLICATION FORKS. J. Biol. Chem. 2012, 287, 35621-35630.

(13) Han, L.; Zi, X.; Garmire, L. X.; Wu, Y.; Weissman, S. M.; Pan, X.; Fan, R. Co-Detection and Sequencing of Genes and Transcripts from the Same Single Cells Facilitated by a Microfluidics Platform. Sci. Rep. 2014, 4, 6485 .

(14) Hirschmann, A.; Lamb, T. A.; Marchal, G.; Padilla, M.; Diebold, J. Simultaneous Analysis of HER2 Gene and Protein on a Single Slide Facilitates HER2 Testing of Breast and Gastric Carcinomas. Am. J. Clin. Pathol. 2012, 138, 837-844.

(15) Lou, X.; Zhang, Y. Mechanism Studies on NanoPCR and Applications of Gold Nanoparticles in Genetic Analysis. ACS Appl. Mater. Interfaces 2013, 5, 6276-6284.

(16) Li, H.; Huang, J.; Lv, J.; An, H.; Zhang, X.; Zhang, Z.; Fan, C.; Hu, J. Nanoparticle PCR: Nanogold-Assisted PCR with Enhanced Specificity. Angew. Chem., Int. Ed. Engl. 2005, 44, 5100-5103.

(17) Sang, F.; Yang, Y.; Wang, H.; Ju, X.; Zhang, Z. Quantum Dots Induce Hot-Start Effects for Taq-Based Polymerase Chain Reaction. J. Biomed. Sci. Eng. 2012, 05, 295-301.

(18) Bai, Y.; Cui, Y.; Paoli, G. C.; Shi, C.; Wang, D.; Shi, X. Nanoparticles Affect PCR Primarily via Surface Interactions with PCR Components: Using Amino-Modified Silica-Coated Magnetic Nanoparticles as a Main Model. ACS Appl. Mater. Interfaces 2015, 7, 1314213153.

(19) Cai, M.; Li, F.; Zhang, Y.; Wang, Q. One-Pot Polymerase Chain Reaction with Gold Nanoparticles for Rapid and Ultrasensitive DNA Detection. Nano Res. 2010, 3, 557-563.

(20) Kim, D.; Daniel, W. L.; Mirkin, C. A. Microarray-Based Multiplexed Scanometric Immunoassay for Protein Cancer Markers Using Gold Nanoparticle Probes. Anal. Chem. 2009, 81, 9183-9187.

(21) Liang, R.-Q.; Li, W.; Li, Y.; Tan, C.-y.; Li, J.-X.; Jin, Y.-X.; Ruan, K.C. An Oligonucleotide Microarray for MicroRNA Expression Analysis Based on Labeling RNA with Quantum Dot and Nanogold Probe. Nucleic Acids Res. 2005, 33, No. e17.

(22) Hemby, S. E.; Lynch, W. J.; Tannu, N. S. Novel Methodologies: Proteomic Approaches in Substance Abuse Research. In Addiction Medicine: Science and Practice; Johnson, B. A., Ed.; Springer: New York, 2011; pp 359-378.

(23) Yuan, X.; Luo, Z.; Zhang, Q.; Zhang, X.; Zheng, Y.; Lee, J. Y.; Xie, J. Synthesis of Highly Fluorescent Metal ( $\mathrm{Ag}, \mathrm{Au}, \mathrm{Pt}$, and $\mathrm{Cu}$ )
Nanoclusters by Electrostatically Induced Reversible Phase Transfer. ACS Nano 2011, 5, 8800-8808.

(24) Tsoi, K. M.; Dai, Q.; Alman, B. A.; Chan, W. C. W. Are Quantum Dots Toxic? Exploring the Discrepancy between Cell Culture and Animal Studies. Acc. Chem. Res. 2013, 46, 662-671.

(25) Yong, K.-T.; Law, W.-C.; Hu, R.; Ye, L.; Liu, L.; Swihart, M. T.; Prasad, P. N. Nanotoxicity Assessment of Quantum Dots: From Cellular to Primate Studies. Chem. Soc. Rev. 2013, 42, 1236-1250.

(26) Zhang, Z.; Liu, Y.; Liu, P.; Yang, L.; Jiang, X.; Luo, D.; Yang, D. Non-invasive detection of gastric cancer relevant $\mathrm{d}$-amino acids with luminescent DNA/silver nanoclusters. Nanoscale 2017, 9, 1936719373.

(27) Govindaraju, S.; Ankireddy, S. R.; Viswanath, B.; Kim, J.; Yun, K. Fluorescent Gold Nanoclusters for Selective Detection of Dopamine in Cerebrospinal fluid. Sci. Rep. 2017, 7, 40298.

(28) Meng, L.; Zhu, Q.; Yin, J.-H.; Xu, N. Polyethyleneimine protected silver nanoclusters luminescence probe for sensitive detection of cobalt (II) in living cells. J. Photochem. Photobiol., B 2017, 173, 508-513.

(29) Pyo, K.; Ly, N. H.; Yoon, S. Y.; Shen, Y.; Choi, S. Y.; Lee, S. Y.; Joo, S.-W.; Lee, D. Highly Luminescent Folate-Functionalized Au22 Nanoclusters for Bioimaging. Adv. Healthcare Mater. 2017, 6, 1700203.

(30) Shen, D.; Henry, M.; Trouillet, V.; Comby-Zerbino, C.; Bertorelle, F.; Sancey, L.; Antoine, R.; Coll, J.-L.; Josserand, V.; Le Guével, X. Zwitterion functionalized gold nanoclusters for multimodal near infrared fluorescence and photoacoustic imaging. APL Mater. 2017, 5, 053404.

(31) Lin, C.-A. J.; Yang, T.-Y.; Lee, C.-H.; Huang, S. H.; Sperling, R. A.; Zanella, M.; Li, J. K.; Shen, J.-L.; Wang, H.-H.; Yeh, H.-I.; Parak, W. J.; Chang, W. H. Synthesis, Characterization, and Bioconjugation of Fluorescent Gold Nanoclusters toward Biological Labeling Applications. ACS Nano 2009, 3, 395-401.

(32) Lu, Y.; Chen, W. Progress in the Synthesis and Characterization of Gold Nanoclusters. In Gold Clusters, Colloids and Nanoparticles I; Mingos, D. M. P., Ed.; Springer International Publishing: Cham, 2014; pp 117-153.

(33) Costa, M. N.; Veigas, B.; Jacob, J. M.; Santos, D. S.; Gomes, J.; Baptista, P. V.; Martins, R.; Inácio, J.; Fortunato, E. A Low Cost, Safe, Disposable, Rapid and Self-Sustainable Paper-Based Platform for Diagnostic Testing: Lab-on-Paper. Nanotechnology 2014, 25, 094006.

(34) Liana, D. D.; Raguse, B.; Gooding, J. J.; Chow, E. Recent Advances in Paper-Based Sensors. Sensors 2012, 12, 11505-11526.

(35) Guion, C. E.; Ochoa, T. J.; Walker, C. M.; Barletta, F.; Cleary, T. G. Detection of Diarrheagenic Escherichia Coli by Use of Melting-Curve Analysis and Real-Time Multiplex PCR. J. Clin. Microbiol. 2008, 46, $1752-1757$.

(36) Sahoo, A. K.; Sailapu, S. K.; Dutta, D.; Banerjee, S.; Ghosh, S. S.; Chattopadhyay, A. DNA-Templated Single Thermal Cycle Based Synthesis of Highly Luminescent Au Nanoclusters for Probing Gene Expression. ACS Sustainable Chem. Eng. 2018, 6, 2142-2151.

(37) Dutta, D.; Sahoo, A. K.; Chattopadhyay, A.; Ghosh, S. S. Bimetallic silver nanoparticle-gold nanocluster embedded composite nanoparticles for cancer theranostics. J. Mater. Chem. B 2016, 4, 793800.

(38) Sahoo, A. K.; Banerjee, S.; Ghosh, S. S.; Chattopadhyay, A. Simultaneous RGB Emitting Au Nanoclusters in Chitosan Nanoparticles for Anticancer Gene Theranostics. ACS Appl. Mater. Interfaces 2014, 6, 712-724.

(39) Chakraborty, S.; Babanova, S.; Rocha, R. C.; Desireddy, A.; Artyushkova, K.; Boncella, A. E.; Atanassov, P.; Martinez, J. S. A Hybrid DNA-Templated Gold Nanocluster For Enhanced Enzymatic Reduction of Oxygen. J. Am. Chem. Soc. 2015, 137, 11678-11687.

(40) Kennedy, T. A. C.; MacLean, J. L.; Liu, J. Blue emitting gold nanoclusters templated by poly-cytosine DNA at low $\mathrm{pH}$ and polyadenine DNA at neutral pH. Chem. Commun. 2012, 48, 6845-6847.

(41) Ishii, M.; Fujita, S.; Yamada, M.; Hosaka, Y.; Kurachi, Y. Phosphatidylinositol 3,4,5-trisphosphate and $\mathrm{Ca}^{2+} /$ Calmodulin Competitively Bind to the Regulators of G-Protein-Signalling (RGS) Domain of RGS4 and Reciprocally Regulate Its Action. Biochem. J. 2005, 385, $65-73$. 
(42) Chaubey, N.; Ghosh, S. S. Molecular Cloning, Purification and Functional Implications of Recombinant GST Tagged hGMCSF Cytokine. Appl. Biochem. Biotechnol. 2013, 169, 1713-1726.

(43) Yao, Q.; Luo, Z.; Yuan, X.; Yu, Y.; Zhang, C.; Xie, J.; Lee, J. Y. Assembly of Nanoions via Electrostatic Interactions: Ion-Like Behavior of Charged Noble Metal Nanoclusters. Sci. Rep. 2014, 4, 3848.

(44) Vanitha, S.; Goswami, U.; Chaubey, N.; Ghosh, S. S.; Sanpui, P. Functional Characterization of Recombinant Human Granulocyte Colony Stimulating Factor (hGMCSF) Immobilized onto Silica Nanoparticles. Biotechnol. Lett. 2016, 38, 243-249. 